\title{
Tunable temperature of reversible phase transitions in a series of heterometallic carboxylate complexes with $\mathrm{CaZn}_{2}$-backbone
}

\author{
S.N. Melnikov, S.A. Nikolaevskii, M.A. Kiskin, I.L. Eremenko \\ N.S. Kurnakov Institute of General and Inorganic Chemistry of the Russian Academy of Sciences (IGIC RAS), Moscow, Russian \\ Federation \\ melnikov.stanislav.mail@gmail.com
}

Last decades there is an ongoing interest in materials with reversible temperature-triggered single-crystal-to-single-crystal phase transitions (SCSC-PT) because of the huge fundamental attraction to this phenomenon as well as the promising practical applications of SCSC-PT as different kinds of switches (e.g. to switch dielectric properties) and memory-devices [1-2].

On the other hand, hydrogen bonds are considered as the powerful and flexible synthon in the field of crystal engineering particularly to obtain materials possessing phase transitions. Hence, keeping it in mind we have obtained a series of complexes with the general formula $\left[\mathrm{CaZn}_{2}(\text { piv })_{6}(\mathrm{~L})_{2}\right]$, where piv - pivalic acid anion, $\mathrm{L}-\mathrm{MeOH}$, EtOH, THF.

Structures of all coordination complexes were unambiguously determined using single-crystal X-Ray Diffraction (XRD) analysis. All compounds form supramolecular 1D-chains either via hydrogen bonds (in the case of $\mathrm{L}=\mathrm{MeOH}$ and $\mathrm{EtOH}$ ) or via $\mathrm{CH}$...O-contacts (in the case of $\mathrm{L}=\mathrm{THF}$ ). The XRD analysis revealed that complex $\left[\mathrm{CaZn}_{2}(\mathrm{piv})_{6}(\mathrm{EtOH})_{2}\right]$ has interesting temperature-induced isosymmetric reversible phase transition (about $250 \mathrm{~K}$ on cooling and about $280 \mathrm{~K}$ on heating) with large hysteresis loop where ethanol groups' rotation being as a main driving force of the process. As a result of rearrangement of hydrogen bonds network, molecules of the low temperature phase become considerably bent with the angle Zn...Ca...Zn $166.45^{\circ}$ compared to completely linear molecules at room temperature.

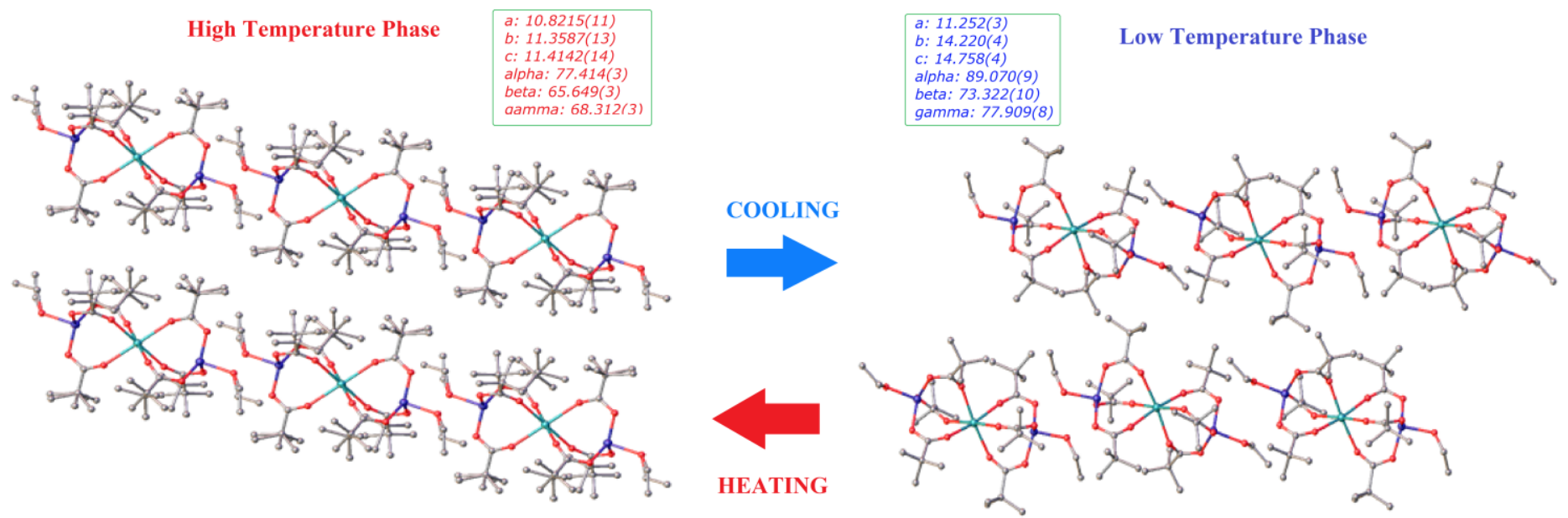

Figure 1. Reversible phase transitions of the complex $\left[\mathrm{CaZn}_{2}(\mathrm{piv})_{6}(\mathrm{EtOH})_{2}\right]$. Left - packing of the high temperature phase (293K), right - packing of the low temperature phase $(100 \mathrm{~K})$.

On the contrary, complex $\left[\mathrm{CaZn}_{2}(\mathrm{piv})_{6}(\mathrm{MeOH})_{2}\right]$ does not show phase transitions in the available temperature range $100 \mathrm{~K}-293 \mathrm{~K}$. The geometry of its molecules is similar to the low temperature phase of $\left[\mathrm{CaZn}_{2}(\mathrm{piv})_{6}(\mathrm{EtOH})_{2}\right]$, but the angle $\mathrm{Zn} \ldots \mathrm{Ca} \ldots \mathrm{Zn}$ is $167.30^{\circ}$ at $150 \mathrm{~K}$. Noteworthy, even though the XRD analysis did reveal rotation of one of the $\mathrm{MeOH}$ groups, the cell parameters are roughly the same between structures obtained at RT and 150K. Apparently, because of much less steric hindrance and spatial degrees of freedom of MeOH groups, the temperature of SCSC-PT lies much higher beyond $293 \mathrm{~K}$ to be revealed.

[1] Ge, J.-Zh, Fu, X.-Q., Hang, T., Ye, Q., \& Xiong R.-G., (2010). Cryst. Growth Des., 10, 8, 3632.

[2] Kendin, M. \& Tsymbarenko, D. (2020). Cryst. Growth Des., 20, 5, 3316.

Keywords: phase transition; coordination complexes; calcium; zinc

This study was supported by the Russian Science Foundation (grant no. 19-13-00436).

Acta Cryst. (2021), A77, C892 